\title{
Central gene expression changes associated with enhanced neuroendocrine and autonomic response habituation to repeated noise stress after voluntary wheel running in rats
}

\author{
Sarah K. Sasse, Tara J. Nyhuis, Cher V. Masini, Heidi E. W. Day and Serge Campeau*
}

Department of Psychology and Neuroscience, University of Colorado, Boulder, CO, USA

Edited by:

Anthony Leicht, James Cook

University, Australia

\section{Reviewed by:}

Anastassios Philippou, National and

Kapodistrian University of Athens,

Greece

Sladjana Dronjak, University of

Belgrade, Serbia

*Correspondence:

Serge Campeau, Department of

Psychology and Neuroscience,

University of Colorado, Muenzinger D244, 345 UCB, Boulder, CO 80309,

USA

e-mail: serge.campeau@

colorado.edu
Accumulating evidence indicates that regular physical exercise benefits health in part by counteracting some of the negative physiological impacts of stress. While some studies identified reductions in some measures of acute stress responses with prior exercise, limited data were available concerning effects on cardiovascular function, and reported effects on hypothalamic-pituitary-adrenocortical (HPA) axis responses were largely inconsistent. Given that exposure to repeated or prolonged stress is strongly implicated in the precipitation and exacerbation of illness, we proposed the novel hypothesis that physical exercise might facilitate adaptation to repeated stress, and subsequently demonstrated significant enhancement of both HPA axis (glucocorticoid) and cardiovascular (tachycardia) response habituation to repeated noise stress in rats with long-term access to running wheels compared to sedentary controls. Stress habituation has been attributed to modifications of brain circuits, but the specific sites of adaptation and the molecular changes driving its expression remain unclear. Here, in situ hybridization histochemistry was used to examine regulation of select stress-associated signaling systems in brain regions representing likely candidates to underlie exercise-enhanced stress habituation. Analyzed brains were collected from active (6 weeks of wheel running) and sedentary rats following control, acute, or repeated noise exposures that induced a significantly faster rate of glucocorticoid response habituation in active animals but preserved acute noise responsiveness. Nearly identical experimental manipulations also induce a faster rate of cardiovascular response habituation in exercised, repeatedly stressed rats. The observed regulation of the corticotropin-releasing factor and brain-derived neurotrophic factor systems across several brain regions suggests widespread effects of voluntary exercise on central functions and related adaptations to stress across multiple response modalities.

Keywords: audiogenic stress, exercise, habituation, glucocorticoid, cardiovascular, in situ hybridization

\section{INTRODUCTION}

Stress is a significant risk factor for numerous physical (Brindley and Rolland, 1989; Khansari et al., 1990; Forsen, 1991; Pasternac and Talajic, 1991; Vanitallie, 2002; Kalantaridou et al., 2004) and psychological (Dunner et al., 1979; Brown et al., 1987; Hammen et al., 1992; Arborelius et al., 1999; Vanitallie, 2002; Swaab et al., 2005) disorders. Remarkably, many of the same disorders precipitated or exacerbated by stress can be prevented or improved by regular physical exercise (Manson et al., 1992; Paffenbarger et al., 1992; Chodzko-Zajko and Moore, 1994; Bérard et al., 1997; Wannamethee et al., 1998; Dunn et al., 2001; Goodwin, 2003), suggesting that routine physical activity may benefit health in part through a stress-mitigating effect (Roth and Holmes, 1985; Brown and Lawton, 1986; Moraska and Fleshner, 2001; Fleshner, 2005). Indeed, exercise can reduce some of the physiological consequences of acute stress under certain experimental conditions (Brown and Siegel, 1988; Dishman et al., 1995, 1997; Moraska and Fleshner, 2001; Greenwood et al., 2003a,b, 2007a,b; Adlard and Cotman, 2004; Campeau et al., 2010; Masini et al.,
2011). However, results are inconsistent across stress stimuli when hypothalamic-pituitary-adrenocortical (HPA) axis-mediated glucocorticoid responses are assessed (Dishman et al., 1995, 1997; Fleshner, 2000; Campisi and Fleshner, 2003; Droste et al., 2003, 2006, 2007; Fediuc et al., 2006; Sasse et al., 2008; Nyhuis et al., 2010), and only limited data are available with regard to cardiovascular reactivity (Morimoto et al., 2000; Masini et al., 2011). Collectively, these findings argue against generalized reductions in acute stress sensitivity by prior exercise, and rather point to complex regulation involving selective modulation of responses to some, but not all, acute stress stimuli. How such a high degree of regulatory specificity is conferred by regular exercise remains to be understood.

While many stress-responsive systems regulate vital physiological functions under both normal and acute stress conditions, it is their sustained, excessive or dysregulated activation by repeated stress that is most strongly associated with pathogenesis (Chrousos and Gold, 1992; Tsigos and Chrousos, 1994; Charmandari et al., 2005). Repeated exposure to the same stressor 
is often accompanied by a progressive decrease in response amplitude, or habituation, which is considered an adaptation that lessens the physiological toll of repeatedly activating stressresponsive systems (Armario et al., 1984, 1986; Kant et al., 1985; Melia et al., 1994; Campeau et al., 2002). Dysfunctional response habituation could contribute to increased susceptibility to stress-related pathology. Prior work in our laboratory indicated that habituation of glucocorticoid (Sasse et al., 2008; Nyhuis et al., 2010) and tachycardia (Masini et al., 2011) responses to repeated audiogenic stress is facilitated after chronic voluntary wheel running in rats, lending support to the hypothesis that the health benefits of regular exercise include enhanced adaptive mechanisms that reduce the cumulative impact of repeated or prolonged stress. Habituation of stress responses involves active plastic processes mediated by changes within the central nervous system (Armario et al., 1988; Melia et al., 1994; Akana and Dallman, 1997; Ezzeddine and Glanzman, 2003; Esdin et al., 2010). Enhanced glucocorticoid and cardiovascular response habituation to repeated stress in exercised animals is thus likely to result from regulation at a central level by physical activity. To explore this possibility, in situ hybridization histochemistry was performed on brains collected from animals that displayed exercise-induced facilitation of glucocorticoid response habituation to repeated audiogenic stress (Sasse et al., 2008; Experiment 2). Similar experimental manipulations also produce enhanced cardiovascular response habituation in exercised, repeatedly stressed rats (Masini et al., 2011). The primary goal was to define neuroanatomical regions and associated neurochemical substrates potentially underlying facilitation of response habituation to repeated audiogenic stress by prior exercise. Although correlational, any reliable changes in central gene expression could subsequently be tested for their specific relevance to the regulation of stress adaptation by physical activity.

First, messenger RNA (mRNA) expression of the immediateearly gene FBJ osteosarcoma oncogene (Fos, also known as c-fos) was characterized in select regions based on their prior association with audiogenic stress activation. These included the central control station of HPA axis activation, the paraventricular nucleus of the hypothalamus (PVN), in addition to various cortical (cingulate [CG], infralimbic [IL], orbitofrontal/claustrum [OFC/CL], and prelimbic $[\mathrm{PL}]$ regions of the medial prefrontal cortex $[\mathrm{mPFC}]$ ) and forebrain (septohypothalamic nucleus [SHy] and closely associated ventrolateral septum [LSv], anterior bed nucleus of the stria terminalis [BNST]) areas (Campeau and Watson, 1997; Campeau et al., 2002; Burow et al., 2005). Regions differentially activated by repeated audiogenic stress in exercised vs. sedentary brains could reflect important sites of exerciseinduced regulation associated with stress response habituation. Within many of these regions, additional molecules reported to mediate glucocorticoid or cardiovascular responses to stress and/or to be regulated by stress or regular exercise were also examined for putative transcriptional regulation. These included transcripts of corticotropin-releasing hormone $(\mathrm{Crh})$ and arginine vasopression ( $A v p)$ at the level of the PVN (Timofeeva et al., 2003; Kawashima et al., 2004; Park et al., 2005), Crh in stressrelated extra-hypothalamic regions (e.g., BNST, central [CeA] and basolateral [BLA] amygdaloid nuclei-Antoni, 1993; Gu et al., 2003; Dong and Swanson, 2006; Hauger et al., 2006; Radley et al., 2009; Ulrich-Lai and Herman, 2009), Crh receptor subtypes Crhr1 and Crhr2 (LSv, PVN, BLA and medial amgydaloid nucleus $[\mathrm{MeA}]$, and ventromedial hypothalamic nucleus $[\mathrm{VMH}]$ - Luo et al., 1994; Chalmers et al., 1995; Makino et al., 1995; Imaki et al., 1996; Van Pett et al., 2000), brain-derived neurotrophic factor (Bdnf; hippocampus, PVN-Smith et al., 1995a,b; Neeper et al., 1996; Oliff et al., 1998; Nibuya et al., 1999; Adlard and Cotman, 2004; Farmer et al., 2004; Gomez-Pinella et al., 2008; Nyhuis et al., 2010), and tyrosine receptor kinase B subtype (Trkb), the main receptor for Bdnf, in the hippocampus (Nibuya et al., 1999). Our group previously examined neurotrophin regulation by prior exercise and repeated stress (Nyhuis et al., 2010), but this analysis did not include comparisons in non-stressed and acutely stressed animals, which were available in the current study.

\section{MATERIALS AND METHODS SUBJECTS AND EXPERIMENTAL DESIGN}

Readers are referred to Sasse et al. (2008) (Experiment 2) for explicit details regarding manipulation of animal subjects and experimental design. All animal procedures were reviewed and approved by the Institutional Animal Care and Use Committee of the University of Colorado and conformed to the National Research Council's Guide for the Care and Use of Laboratory Animals (8th Edn., 2011). All efforts were made to minimize animal suffering and the number of animals used. Briefly, following an acclimation period to our colony facility, the 48 young adult ( $\sim 2$ months of age upon arrival), male Sprague-Dawley rats (Harlan, Indianapolis, IN) were divided into six groups matched for body weight ( $n=8$ /group) and individually housed. Three groups were assigned to the Exercise (Ex) condition and given $24 \mathrm{~h}$ unlimited access to a stainless steel running wheel (Nalge Nunc International) attached to the wire lid of their home cages for the 6 weeks prior to and the 11 days of the experimental testing phase. During the same time period, the remaining 3 groups were individually housed in similar cages in the same colony room, but under Sedentary (Sed) conditions, without running wheels in their home cages.

Figure 1 provides a graphic summary of the experimental design. On each of the 3 days prior to the onset of testing, all Ex and Sed animals were pre-exposed to the testing conditions, which involved transporting rats to a separate testing room, placing them within their home cages into assigned acoustic chambers, and exposing them only to the background noise $(\sim 60$ decibel-A scale $[\mathrm{dB}]$ ) generated by the ventilation fans for $30 \mathrm{~min}$. Importantly, Ex rats would be denied running wheel access during all $30 \mathrm{~min}$ stress (or no stress) exposures, so they were habituated to this additional experimental manipulation during these preexposures by placing a long metal rod through both ends of each wheel that completely blocked rotation. Then, on each of 11 consecutive days, rats were transported to the testing room, placed within their home cages into their assigned acoustic chambers, and exposed to one of the following Stress Treatment conditions for $30 \mathrm{~min}$ : $98 \mathrm{~dB}$ noise stress (Ex- or Sed-Repeated Noise, $n=8$ /group), $60 \mathrm{~dB}$ background noise (Ex- or Sed-No Noise, $n=8$ /group), or $60 \mathrm{~dB}$ background noise exposures on the first 10 days followed by a single $98 \mathrm{~dB}$ noise stress presentation on Day 


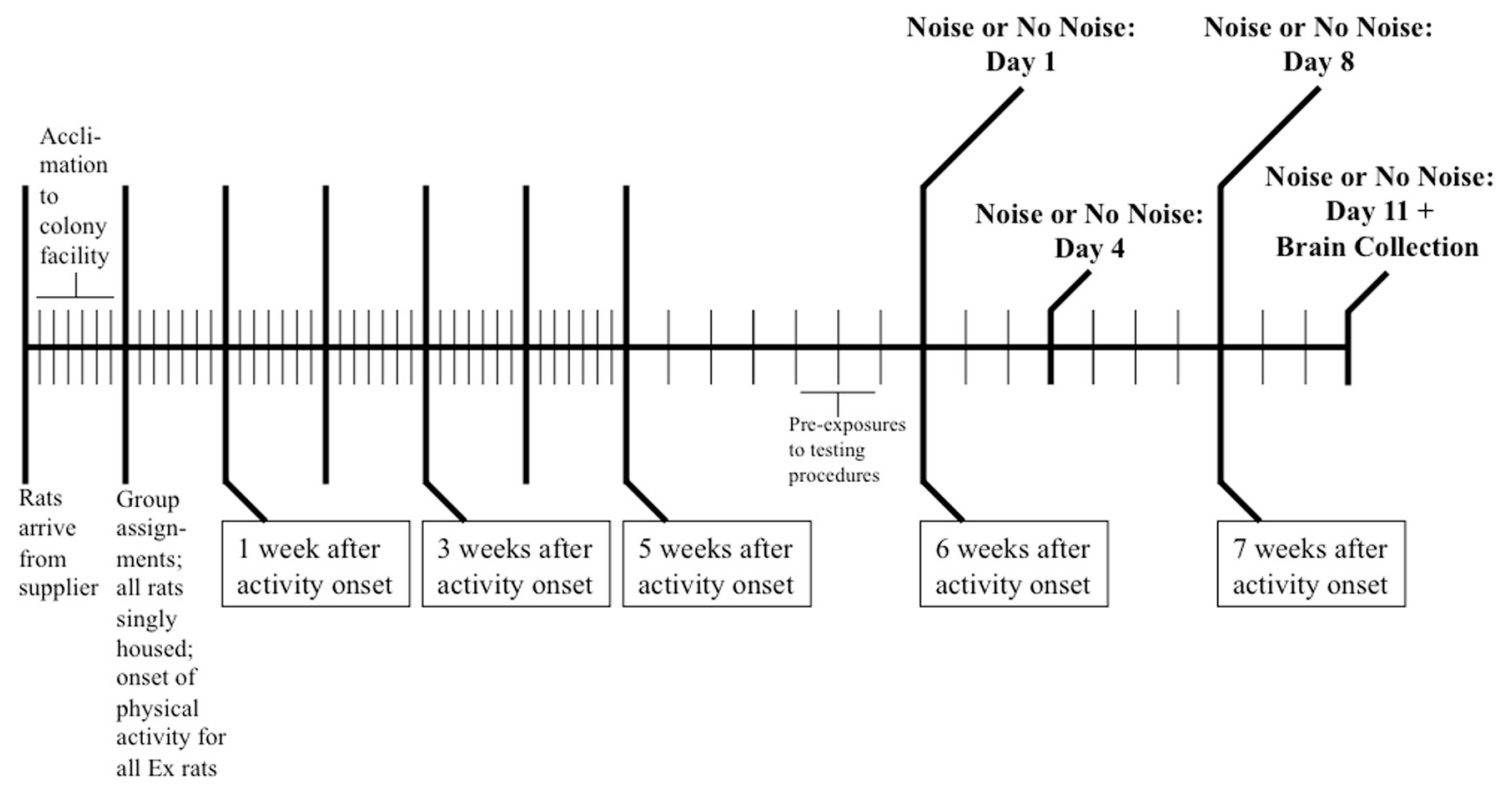

FIGURE 1 | Schematic depicting the experimental design used in the Sasse et al. (2008) study to generate the brain tissue samples utilized in the present study. Following a 7-day acclimation period to the colony facility, rats were assigned to one of six groups matched for body weight ( $n=8 /$ group) and individually housed. Half of the rats were given unrestricted voluntary access to running wheels in their home cages (Ex) while the remaining animals lived in similar cages without running wheels under sedentary conditions (Sed) for 6 weeks. Rats were then exposed to 11 consecutive daily 30 min 98 dB noise stress (Ex- or Sed-Repeated Noise: $n=8 /$ group) or $60 \mathrm{~dB}$ background noise (Ex- or Sed-No Noise; $n=8 /$ group) presentations, or were presented with 10 consecutive daily 30 min exposures to $60 \mathrm{~dB}$ background noise followed by a single $30 \mathrm{~min} 98 \mathrm{~dB}$ noise stress exposure on Day 11 (Ex- or Sed-Acute Noise; $n=8 /$ group). On each of the 3 days prior to the onset of testing, all rats were pre-exposed to the acoustic chambers in order to familiarize them with the testing conditions. Immediately following the stress (or no stress) exposure on Day 11, animals were decapitated and brains were collected for analysis by in situ hybridization histochemistry. Each vertical line in the schematic represents 1 day.
11 (Ex- or Sed-Acute Noise, $n=8$ /group). Running wheels of all Ex rats were locked during each noise (or no noise) exposure, after which wheels were immediately unlocked and all animals were returned to the colony. Immediately following the final $30 \mathrm{~min}$ $98 \mathrm{~dB}$ or background noise exposure on Day 11, all rats were killed by decapitation (without anesthesia), and brains were removed immediately and frozen in isopentane chilled to -30 to $-40^{\circ} \mathrm{C}$ prior to storage at $-80^{\circ} \mathrm{C}$ until further processing.

\section{In situ HYBRIDIZATION HISTOCHEMISTRY}

Ten micron coronal sections of collected brains were cut on a cryostat (Leica model 1850, Wetzlar, Germany), thaw-mounted onto poly-L-lysine-coated slides, and stored at $-80^{\circ} \mathrm{C}$ until processed. Slides were first fixed in a phosphate-buffered $4 \%$ paraformaldehyde solution for $1 \mathrm{~h}$, and then rinsed 3 times in 2X sodium saline citrate (SSC), acetylated for $10 \mathrm{~min}$ in $0.1 \mathrm{M}$ triethanolamine containing $0.25 \%$ acetic anhydride, rinsed in distilled water, and dehydrated in graded ethyl alcohol concentrations. ${ }^{35} \mathrm{~S}$-labeled cRNA riboprobes were generated for Fos, Crh, Crhr1, Crhr2, Avp, Bdnf, and Trkb from cDNA subclones in transcription vectors using standard in vitro transcription methodology. The rat Fos (courtesy of Dr. T. Curran, St. Jude Children's Research Hospital, Memphis, TN) and Crh (courtesy of Dr. R. T. Thompson, University of Michigan) cDNA clones were subcloned in pGem $3 Z$ and cut with HindIII to yield 680 nucleotide (nt) and $770 \mathrm{nt}$ cDNA templates, respectively. The rat Crhr1 cDNA clone (Dr. J. P. Herman, University of Cincinnati) was subcloned in pCR-Blunt II-Topo and cut with BamHI to yield a $345 \mathrm{nt}$ cDNA template. The rat Crhr2 (courtesy of Dr. R. T. Thompson, University of Michigan) and Trkb (courtesy of Dr. D. McKinnon, SUNY, Stony Brook) cDNA clones were subcloned in pBluescript SK and cut with HindIII to yield $899 \mathrm{nt}$ and $306 \mathrm{nt}$ cDNA templates, respectively. The rat Avp cDNA clone (courtesy of Dr. T. G. Sherman, Georgetown University Medical Center) was subcloned into pGem 3 and cut with EcoRI to yield a 235 nt cDNA template. The rat $B d n f$ cDNA clone (courtesy of Dr. J. P. Herman, University of Cincinnati) was subcloned in pBluescript and cut with PvuII to yield a 759 nt cDNA template.

Copy riboprobes were labeled in a reaction mixture consisting of $1 \mu \mathrm{g}$ of the appropriate linearized plasmid, $1 \mathrm{X} \mathrm{T3,} \mathrm{T7,} \mathrm{or}$ SP6 transcription buffer (Promega), $125 \mu \mathrm{Ci}{ }^{35}$ S-UTP, $150 \mu \mathrm{M}$ NTP's (ATP, CTP, and GTP), $12.5 \mathrm{mM}$ dithiothreitol, $20 \mathrm{U}$ RNase inhibitor, and $6 \mathrm{U}$ of T3 (for Crhr2, Bdnf, and Trkb), T7 (for Fos, Crh, and Crhr1), or SP6 (for Avp) RNA polymerase. The reaction was allowed to proceed for $2 \mathrm{~h}$ at $37^{\circ} \mathrm{C}$, after which probe was separated from free nucleotides over a Sephadex G50-50 column. Riboprobes were diluted in hybridization buffer consisting of $50 \%$ formamide, $10 \%$ dextran sulfate, $2 \mathrm{X}$ SSC, $50 \mathrm{mM}$ sodium phosphate buffer ( $\mathrm{pH} 7.4), 1 \mathrm{X}$ Denhardt's solution, and $0.1 \mathrm{mg} / \mathrm{ml}$ yeast tRNA, to yield $\sim 1-2 \times 10^{6} \mathrm{dpm} / 70 \mu \mathrm{l}$ buffer. Diluted probe $(70 \mu \mathrm{l})$ was applied to tissue sections on each slide, which were then coverslipped, placed in sealed plastic boxes lined with filter paper moistened with $60 \%$ formamide in distilled water, and incubated overnight $(12-18 \mathrm{~h})$ at $55^{\circ} \mathrm{C}$. Coverslips were then 
removed, and slides were rinsed 3 times in 2X SSC before being incubated in a solution containing RNase A $(2.0 \mu \mathrm{g} / \mathrm{ml})$ for $1 \mathrm{~h}$ at $37^{\circ} \mathrm{C}$. Slides were next washed successively in $2 \mathrm{X}, 1 \mathrm{X}, 0.5 \mathrm{X}$, and $0.1 \mathrm{X}$ SSC for $5 \mathrm{~min}$ each, and then incubated in $0.1 \mathrm{X}$ SSC for $1 \mathrm{~h}$ at $65^{\circ} \mathrm{C}$. They were subsequently returned to room temperature in 2 rinses of $0.1 \mathrm{X}$ SSC for 5-10 min each prior to being dehydrated in graded ethyl alcohols and air-dried. Slides were then exposed to Kodak MR X-ray film for optimized exposure times.

Control experiments were performed on tissue sections pretreated with RNase A $\left(2.0 \mu \mathrm{g} / \mathrm{ml}\right.$ at $37^{\circ} \mathrm{C}$ for $\left.1 \mathrm{~h}\right)$ prior to hybridization; this treatment prevented labeling. Additionally, some control sections were hybridized with the sense cRNA strands, which in all cases did not lead to significant hybridization to tissue sections (data not shown). For each riboprobe, two to three slides (4-6 sections/slide) representing a given brain region from each rat included in the study were processed simultaneously to allow for direct comparisons in the same regions. In more cases than not, multiple in situ hybridizations were performed for the same target mRNA at different levels of the brain with all animals represented, which reduced the effects of technical variation within regions, but limited the ability to make direct comparisons between different regions.

\section{IMAGE ANALYSIS}

Semi-quantitative densitometric analyses were performed on digitized images from X-ray films in the linear range of the gray values obtained with our acquisition system (Northern Light lightbox model B95 [Imaging Res. Inc., St. Catharines, Ontario], a SONY TV camera model XC-ST70 fitted with a Navitar 7000 zoom lens [Rochester, NY], connected to an LG3-01 frame grabber [Scion Corp., Frederick, MD] inside a Dell Dimension 500, captured with Scion Image beta rel. 4.02). Signal pixels in a region of interest were defined as being 3.5 standard deviations above the mean gray value of the representative background, which was set by a cell- and/or signal- poor area close to the region of interest. Mean integrated gray values were computed from the product of the number of pixels comprising the positive signal and their average gray level within the region of interest.

The panels in the left column of Figures 2A,E,I,M provide schematic representations of the brain that were adapted from The Rat Brain in Stereotaxic Coordinates (CD-ROM; Paxinos and Watson, 2005) atlas, with permission from Elsevier. The right sides of these coronal sections are labeled for the regions of interest in which semi-quantitative analyses were performed, while the left sides of the same sections illustrate the templates that were consistently used to define these regions. For example, panel A represents a section at the level of the prefrontal cortex (PFC; $3.24 \mathrm{~mm}$ anterior to bregma, as designated in the lower right corner), in which Fos mRNA expression was analyzed in: the prelimbic $(\mathrm{PL}) \mathrm{PFC}$, designated by a $50 \times 60$ pixel rectangle template; IL PFC, designated by a $40 \times 50$ pixel ellipse; the region encompassing the orbitofrontal cortex and claustrum (OFC/CL), designated by a $110 \times 60$ pixel ellipse; and the cingulate $(\mathrm{CG})$ PFC, for which a trapezoidal template was designed using the Paxinos and Watson atlas for guidance. For each riboprobe, 4-12 bilateral measurements were made within each relevant region of interest (as defined by the template boundaries illustrated in Figure 2) on appropriate sections from each animal. These values were averaged to obtain the mean integrated gray value per region for each rat, which provided the relative mRNA expression level. This analytic method gives relative semi-quantitative results that are comparable to performing a quantitative grain analysis on photographic emulsion-dipped sections (Day et al., 2005). Occasionally, sections or slides for a specific animal were missing, damaged, or otherwise inappropriate for analysis following these multiple levels of processing and were therefore excluded. These instances will be explicitly stated in the appropriate Results section.

\section{STATISTICAL ANALYSES}

All statistical analyses were performed using the Statistical Analysis Software (SAS) program. Two-way (Activity Status $\times$ Stress Treatment) ANOVAs were used to analyze the various target mRNA expression levels in the brain regions of interest. These were followed by Scheffés post-hoc multiple means comparisons to determine the source of reliable effects when present. Statistical significance for all analyses was set at $p \leq 0.05$.

\section{RESULTS}

\section{REGIONAL FoS mRNA INDUCTION}

Expression levels and basic statistical comparisons of Fos mRNA measured in several brain regions of exercised and sedentary rats immediately following the last of 11 consecutive daily noise (Repeated Noise) or background noise (No Noise) exposures, or an acute noise stress presentation on Day 11 (Acute Noise), are presented in Table 1. Of the eight regions analyzed, six displayed a similar pattern of Fos mRNA induction, in which only rats from the acutely exposed groups demonstrated reliable induction that was greater than that of the repeatedly exposed and no noise control groups, which did not differ from each other (see panels B-D of Figure 2). These regions included the PVN [main effect of Stress Treatment: $F_{(2,38)}=35.73, p<0.0001$ ], LSv [Stress Treatment: $F_{(2,42)}=55.77, p<0.0001$ ], SHy [Stress Treatment: $\left.F_{(2,42)}=82.27, p<0.0001\right]$, ventrolateral aspect of the anterior BNST [vBNST; Stress Treatment: $F_{(2,42)}=23.64$, $p<0.0001$ ], and the PL [Stress Treatment: $F_{(2,38)}=6.93, p=$ 0.0027] and IL [Stress Treatment: $F_{(2,38)}=17.15, p<0.0001$ ] regions of the $\mathrm{mPFC}$, as evidenced by Two-Way ANOVAs and confirmed and further characterized by Scheffés post-hoc analyses (all p's $\leq 0.05$ ). Additional Two-Way ANOVAs showed that group differences in Fos mRNA expression in the OFC/CL region did not reach statistical significance, and while there was a significant Activity Status $\times$ Stress Treatment interaction effect on Fos mRNA expression in the CG $\left[F_{(2,38)}=3.28, p=0.0487\right]$, Scheffés post-hoc analyses did not reveal any reliable differences among pair-wise comparisons. Of the four $\mathrm{mPFC}$ regions examined for Fos mRNA induction, the following groups had at least one animal excluded from the analysis: Sed-Repeated Noise $(n=$ $7)$, Ex-No Noise $(n=7)$, and Ex-Repeated Noise $(n=6)$. The following groups had at least one animal excluded from the analysis in the PVN: Sed-Repeated Noise $(n=7)$ and Ex-Repeated Noise $(n=7)$. 


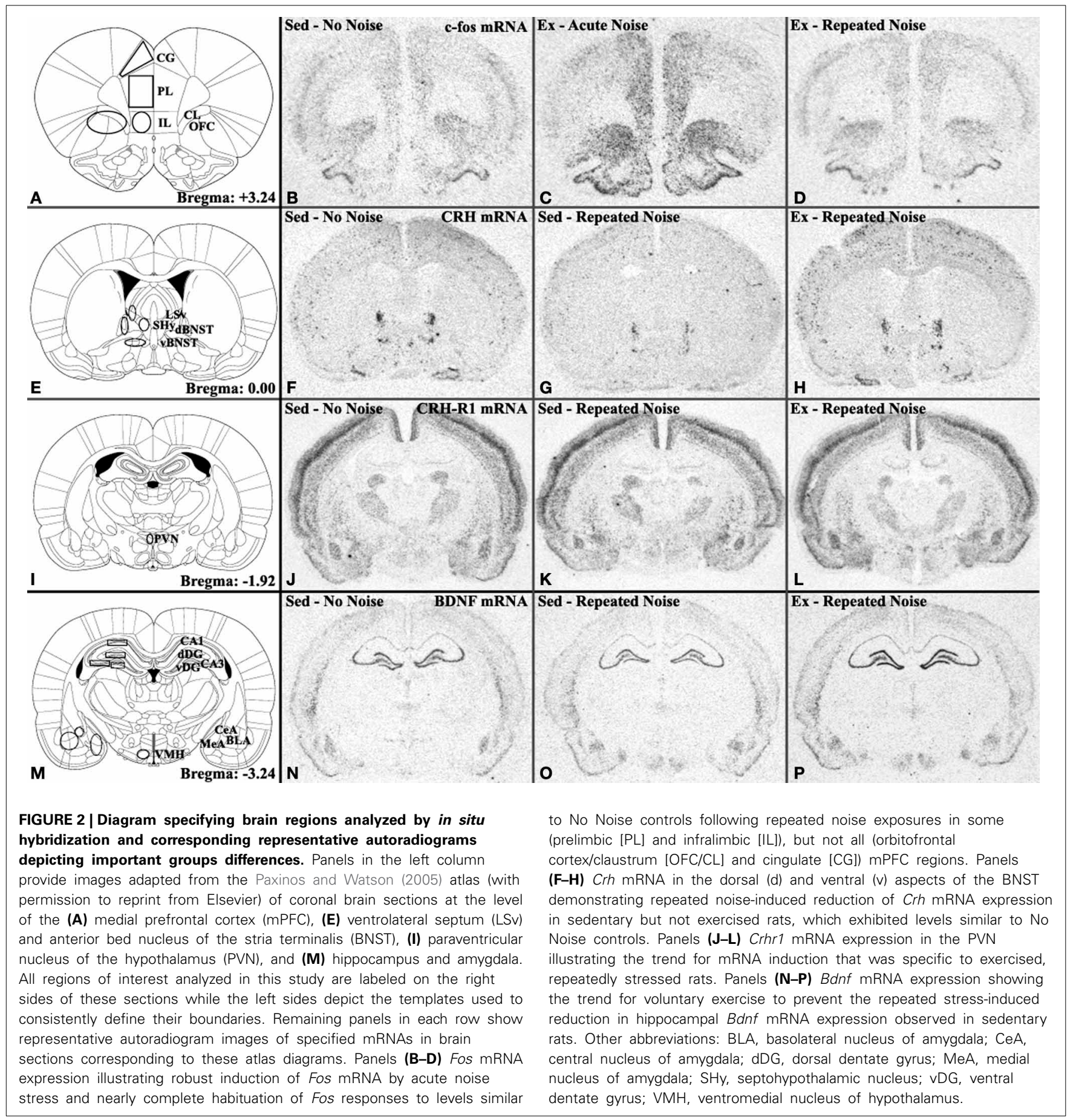

\section{HYPOTHALAMIC Crh AND Avp mRNA EXPRESSION}

Crh mRNA expression levels in the PVN are presented in Table 2. A Two-Way ANOVA revealed significant Activity Status $\left[F_{(1,42)}=6.07, p=0.0180\right]$, Stress Treatment $\left[F_{(2,42)}=7.28\right.$, $p=0.0019]$, and Activity Status $\times$ Stress Treatment $\left[F_{(2,42)}=\right.$ 5.17, $p=0.0098$ ] effects on Crh mRNA expression in this key locus of stress response integration. Specifically, when controlling for Stress Treatment, Ex rats exhibited reliably lower PVN-Crh

mRNA expression than Sed rats, and while holding Activity Status constant, animals in the Repeated Noise groups had significantly greater mRNA expression than those exposed to Acute Noise, although neither of these two groups differed reliably from the No Noise controls (Scheffé, $p$ 's $\leq 0.05$ ). The significant interaction effect reflects that, while acute and repeated noise stress exposure had little effect on Crh mRNA expression in the PVN of Ex rats, the Sed rats acutely exposed to 
Table 1 | Stress and voluntary exercise effects on central Fos mRNA expression.

\begin{tabular}{|c|c|c|c|c|c|c|}
\hline & \multicolumn{3}{|c|}{ Sed } & \multicolumn{3}{|c|}{ Ex } \\
\hline & No & Acute & Repeated & No & Acute & Repeated \\
\hline \multicolumn{7}{|c|}{ Fos mRNA } \\
\hline \multicolumn{7}{|c|}{ Cortex } \\
\hline CG & $141(50)$ & $243(58)$ & $194(41)$ & $288(93)$ & $163(23)$ & $94(17)$ \\
\hline $\mathrm{IL}^{*}{ }^{\dagger}$ & $19(5.4)^{a}$ & $101(18)^{b}$ & $37(9.5)^{a}$ & $38(13)^{a}$ & $78(9.6)^{b}$ & $34(7.2)^{a}$ \\
\hline $\mathrm{OFC/CL}$ & $369(86)$ & $568(105)$ & 577 (159) & $554(146)$ & $412(145)$ & $339(51)$ \\
\hline $\mathrm{PL}^{*}+$ & $105(38)^{a}$ & $333(67)^{b}$ & $184(60)^{\mathrm{a}}$ & $182(52)^{a}$ & $281(36)^{b}$ & $132(24)^{\mathrm{a}}$ \\
\hline \multicolumn{7}{|l|}{ Forebrain } \\
\hline vBNST*† & $4.3(1.2)^{a}$ & $51(11)^{b}$ & $5.6(1.0)^{a}$ & $6.0(2.3)^{a}$ & $43(11)^{b}$ & $12(5.3)^{a}$ \\
\hline $\mathrm{SHy}^{*}+$ & $2.3(1.2)^{a}$ & $178(18)^{b}$ & $16(5.8)^{a}$ & $3.8(1.5)^{a}$ & $144(27)^{\mathrm{b}}$ & $18(6.3)^{a}$ \\
\hline LSV*† & $6.7(2.6)^{\mathrm{a}}$ & $248(35)^{b}$ & $40(22)^{a}$ & $20(6.4)^{a}$ & $225(33)^{\mathrm{b}}$ & $57(16)^{\mathrm{a}}$ \\
\hline
\end{tabular}

\section{Hypothalamus}

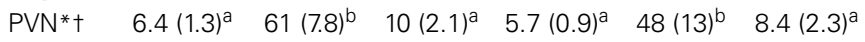

Mean relative Fos MRNA expression in indicated brain regions of exercised (EX) and sedentary (Sed) rats exposed to no, acute, or repeated noise stress. Group means are mean integrated gray values/100 ( \pm 1 s.e.m.), presented as arbitrary units. $C G$, cingulate cortex; IL, infralimbic cortex; OFC/CL, orbitofrontal cortex/claustrum; PL, prelimbic cortex; VBNST, ventrolateral bed nucleus of stria terminalis; $S H y$, septohypothalamic nucleus; LSv, ventrolateral septum; PVN, paraventricular nucleus of hypothalamus.

${ }^{*}$ Omnibus ANOVA, $p \leq 0.05$.

${ }^{\dagger}$ Two-Way ANOVA: significant main effect of Stress Treatment $(p \leq 0.05)$;

$a, b$ across each row, Stress Treatment group means with same (or no) letter symbol were not statistically different (Scheffé, $p \leq 0.05$ ).

noise showed a reliable reduction in mRNA expression as compared to the other two Sed groups, which did not differ (Scheffé, $p \leq 0.05)$. A graphic representation of $\mathrm{Crh}$ mRNA expression in the PVN is depicted in Figure 3A to help illustrate this interaction. Avp mRNA expression was abundant in both the paraventricular and supraoptic nuclei of the hypothalamus in all groups. However, the extent of this expression was not reliably affected by Activity Status or Stress Treatment in either structure, as evidenced by non-significant Two-Way ANOVAs (data not shown).

\section{EXTRA-HYPOTHALAMIC Crh mRNA EXPRESSION}

Table 2 also depicts relative Crh mRNA expression levels in specified extra-hypothalamic regions. In the dorsal aspect of the anterior BNST (dBNST), a significant Activity Status $\times$ Stress Treatment interaction effect was found on Crh mRNA expression $\left[F_{(2,42)}=8.42, p=0.0008\right]$. In general, while expression was decreased by the repeated noise stress in Sed rats, it was relatively unaffected, and even somewhat increased, in Ex animals exposed to the same repeated stress paradigm (see panels F-H of Figure 2). The only statistically significant group difference revealed by Sheffés post-hoc analyses, however, was that Crh mRNA expression was reliably lower in the Sed-Repeated Noise group than all other groups $(p \leq 0.05)$, which did not differ amongst each other. Crh mRNA levels in the dBNST are depicted in Figure 3B to aid in the visualization of this interaction. A similar expression pattern was observed in the vBNST and
Table 2 | Effects of stress and wheel running on central CRH signaling.

\begin{tabular}{|c|c|c|c|c|c|c|}
\hline & \multicolumn{3}{|c|}{ Sed } & \multicolumn{3}{|c|}{ Ex } \\
\hline & No & Acute & Repeated I & No & Acute & Repeated \\
\hline \multicolumn{7}{|c|}{ Crh mRNA } \\
\hline \multicolumn{7}{|l|}{ Forebrain } \\
\hline $\mathrm{dBNST}^{*} \boldsymbol{q}$ & 77 (9.1) & $74(11)$ & $31(2.7)$ & 55 (9.7) & $47(6.0)$ & $68(10)$ \\
\hline VBNST*ף & $56(7.5)$ & $43(5.2)$ & $28(6.9)$ & $34(3.8)$ & $32(3.7)$ & $52(6.4)$ \\
\hline
\end{tabular}

\section{Hypothal.}

$\mathrm{PVN}^{*} \neq+$ ๆ $289(11)^{\mathrm{a}, \mathrm{b}} 225(9.1)^{\mathrm{b}} 293(12)^{\mathrm{a}} 234(13)^{\mathrm{a}, \mathrm{b}} 242(10)^{\mathrm{b}} 261(13)^{\mathrm{a}}$

\begin{tabular}{|c|c|c|c|c|c|c|}
\hline \multicolumn{7}{|c|}{ Amygdala } \\
\hline $\mathrm{CeA}^{*} \boldsymbol{\eta}$ & $136(16)$ & $137(24)$ & $73(10)$ & $93(16)$ & $67(15)$ & $119(18)$ \\
\hline \multicolumn{7}{|c|}{ Crhr1 mRNA } \\
\hline \multicolumn{7}{|c|}{ Hypothal. } \\
\hline PVN & $31(4.5)$ & $33(8.1)$ & $33(4.5)$ & $28(3.5)$ & $24(4.0)$ & 47 (8.3) \\
\hline
\end{tabular}

Amygdala
$\begin{array}{lllllll}\text { MeA } & 191(19) & 159(17) & 173(20) & 191(22) & 152(30) & 156(12) \\ \text { BLA } & 148(19) & 99(8.5) & 147(14) & 132(19) & 110(27) & 116(12) \\ \text { Crhr2 mRNA } & & & & & \\ \text { Forebrain } \\ \text { LSv } \quad 673(83) & 636(106) & 490(111) & 445(65) & 585(122) & 775(129)\end{array}$

\section{Hypothal.}

$V_{M H *}^{*} \quad 329(19) \quad 322(29) \quad 309(20) \quad 250(9.9) \quad 284(16) \quad 258(14)$

\begin{tabular}{|c|c|c|c|c|c|c|}
\hline \multicolumn{7}{|c|}{ Amygdala } \\
\hline $\mathrm{MeA}$ & 369 (39) & $344(42)$ & 332 (32) & $358(24)$ & $378(36)$ & 335 (48) \\
\hline
\end{tabular}

Mean relative expression of $\mathrm{Crh}, \mathrm{Crhr}$, and Crhr2 mRNAs in indicated brain regions of Ex and Sed rats following no, acute, or repeated audiogenic stress. Group means are mean integrated gray values $/ 100$ ( \pm 1 s.e.m.), presented as arbitrary units. dBNST, dorsal BNST; Hypothal., hypothalamus; CeA, central nucleus of amygdala; $M e A$ and $B L A$, medial and basolateral nuclei of amygdala; $V M H$, ventromedial nucleus of hypothalamus.

${ }^{*}$ Omnibus ANOVA, $p \leq 0.05$.

Two-Way ANOVA: ${ }^{*}$ significant main effect of Activity Status, ${ }^{\dagger}$ significant main effect of Stress Treatment $(p \leq 0.05)$; ${ }^{a}, b$ across each row, Stress Treatment group means with same (or no) letter symbol(s) were not statistically different (Scheffé, $p \leq 0.05$ ). 1/significant Activity Status $x$ Stress Treatment interaction $(p \leq 0.05)$; group differences are not indicated by letter symbols here but rather presented in the Results section and illustrated in Figure $\mathbf{3}$.

the CeA, and while significant Activity Status $\times$ Stress Treatment interaction effects were uncovered for both regions by Two-Way ANOVAs [vBNST: $F_{(2,42)}=9.27, p=0.0005$; CeA: $F_{(2,41)}=$ $6.62, p=0.0032]$, none of the post-hoc pair-wise comparisons revealed reliable group differences (Scheffé, all $p$ 's $>0.05$ ). One animal in the Ex-Acute Noise group was excluded from the analysis of $\mathrm{Crh}$ mRNA expression in the CeA $(n=7)$.

\section{Crh RECEPTOR mRNAs}

Two-Way ANOVAs revealed no significant differences in Crhr1 mRNA levels in the MeA or BLA. Similarly, no reliable effects of Activity Status or Stress Treatment were found with respect to Crhrl mRNA expression in the PVN when analyzing all six experimental groups (see Table 2). Interestingly, when comparing only the Ex groups using a One-Way ANOVA for Stress Treatment, 


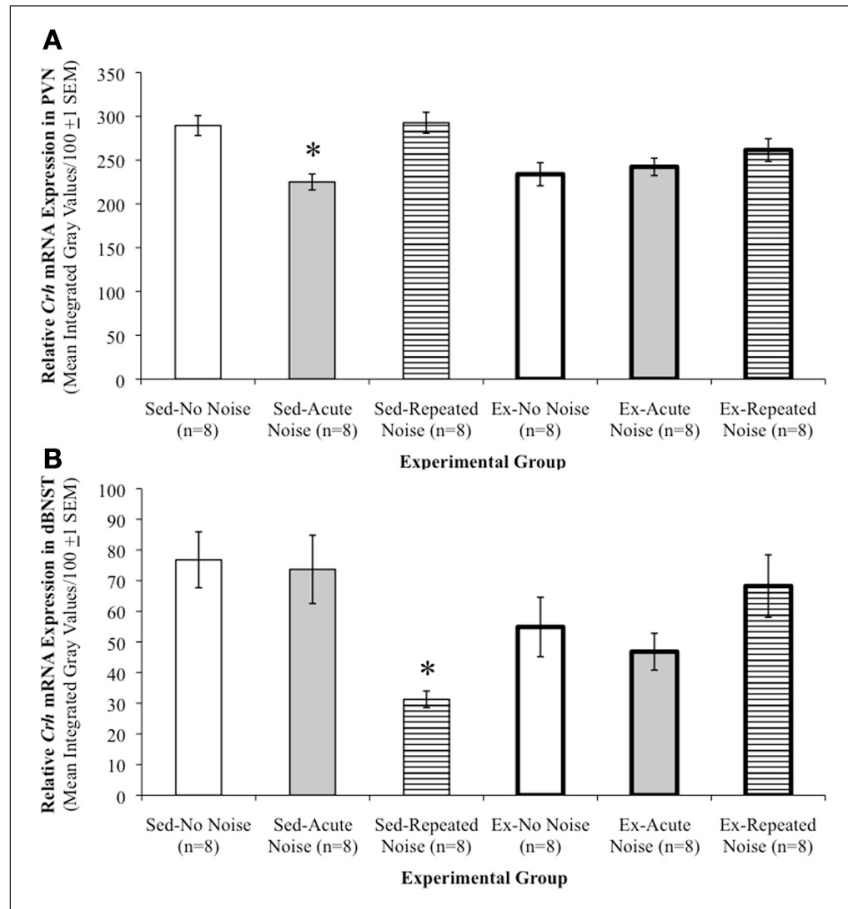

FIGURE 3 | Stress-induced $C r h$ regulation in the PVN and dBNST is different in exercised compared to sedentary rats. (A) Relative $\mathrm{Crh}$ mRNA expression levels in the paraventricular nucleus of the hypothalamus (PVN). Significant main effects of Activity Status and Stress Treatment were observed, with reliably lower PVN-Crh mRNA expression levels in Ex as compared to Sed rats, and significantly greater expression levels in Repeated as compared to Acute Noise groups, although neither of these two groups differed reliably from the No Noise controls. The interaction effect was also significant, such that, while acute and repeated noise stress exposure had little effect on Crh mRNA expression in the PVN of Ex rats, the Sed rats acutely exposed to noise showed a reliable reduction in mRNA expression as compared to the other two Sed groups, which did not differ. Group means are mean integrated gray values/100 ( \pm 1 s.e.m.), presented as arbitrary units. ${ }^{*} p \leq 0.05$ vs. Sed-No Noise and Sed-Repeated Noise. (B) Relative Crh mRNA expression levels in the dorsal aspect of the anterior bed nucleus of the stria terminalis (dBNST). A significant Activity Status $\times$ Stress Treatment interaction effect was found such that, while expression levels were decreased by the repeated noise stress in Sed rats, they were relatively unaffected, and even slightly increased, in Ex animals exposed to the same repeated stress paradigm. A similar pattern in CRH mRNA expression was also observed in the anteroventral portion of the BNST (vBNST), as well as the central nucleus of the amygdala (CeA; see

Table 2). Group means are mean integrated gray values/100 ( \pm 1 S.E.M.), presented as arbitrary units. ${ }^{*} p \leq 0.05$ vs. all other experimental groups, which were not reliably different amongst each other.

a significant main effect was uncovered $\left[F_{(2,21)}=4.67, p=\right.$ 0.0210], such that Crhr1 mRNA expression was significantly greater in the PVN of Ex-Repeated Noise as compared to ExAcute Noise animals (Scheffé, $p \leq 0.05$ ), although neither of these groups differed reliably from the Ex-No Noise group (see panels J-L of Figure 2). A Two-Way ANOVA revealed a significant main effect of Activity Status $\left[F_{(1,40)}=13.88, p=0.0006\right]$ on Crhr2 mRNA expression in the $\mathrm{VMH}$, with reliably lower expression in brains of Ex compared to Sed animals. The following groups had at least one animal excluded from the analysis in the VMH:
Table 3 | Stress and wheel running regulation of central Bdnf and Trkb mRNA expression.

\begin{tabular}{|c|c|c|c|c|c|c|}
\hline & \multicolumn{3}{|c|}{ Sed } & \multicolumn{3}{|c|}{ Ex } \\
\hline & No & Acute & Repeated & No & Acute & Repeated \\
\hline \multicolumn{7}{|c|}{ Bdnf mRNA } \\
\hline \multicolumn{7}{|c|}{ Hippocampus } \\
\hline CA1 & $8.8(1.7)$ & $6.9(1.1)$ & $4.9(0.9)$ & $8.1(1.5)$ & $9.5(2.3)$ & $9.7(2.1)$ \\
\hline CA3* & $100(8.0)$ & $91(4.9)$ & $82(8.4)$ & 114 (8.4) & $124(12)$ & $124(9.2)$ \\
\hline$d D G^{*} \ddagger$ & $138(7.4)$ & $125(7.4)$ & 115 (16) & 169 (14) & $187(14)$ & $189(12)$ \\
\hline$v D G^{*} \ddagger$ & $113(10)$ & 95 (5.9) & $93(14)$ & $148(17)$ & $170(19)$ & $163(15)$ \\
\hline \multicolumn{7}{|c|}{ Hypothalamus } \\
\hline PVN & $111(15)$ & $113(13)$ & $117(11)$ & $100(16)$ & $118(16)$ & $126(16)$ \\
\hline \multicolumn{7}{|c|}{ Trkb mRNA } \\
\hline \multicolumn{7}{|c|}{ Hippocampus } \\
\hline $\mathrm{CA} 1 * \neq$ & $106(7.2)$ & $96(4.7)$ & $100(7.3)$ & $121(8.2)$ & $118(4.4)$ & $107(3.0)$ \\
\hline CA3 & $82(7.9)$ & $72(7.5)$ & $80(6.6)$ & $97(10)$ & $95(9.0)$ & 87 (5.8) \\
\hline $\mathrm{dDG}$ & $133(9.2)$ & $121(8.0)$ & $129(6.7)$ & $139(9.5)$ & $144(11)$ & $136(3.7)$ \\
\hline vDG & $145(11)$ & 132 (9.9) & $143(8.2)$ & $148(8.6)$ & 155 (9.5) & $136(4.6)$ \\
\hline
\end{tabular}

Mean relative Bdnf and Trkb mRNA expression levels in indicated brain regions of Ex and Sed rats following no, acute, or repeated stress. Group means are mean integrated gray values/100 ( \pm 1 s.e.m.), presented as arbitrary units. $d D G$ and $v D G$, dorsal and ventral blades of dentate gyrus, respectively.

*Omnibus ANOVA, $p \leq 0.05$.

Two-Way ANOVA: ${ }^{*}$ significant main effect of Activity Status $(p \leq 0.05)$.

Sed-Acute Noise $(n=7)$ and Sed-Repeated Noise $(n=7)$. Crhr2 mRNA levels were not reliably different between treatment groups in the LSv or MeA (Table 2).

\section{Bdnf AND Trkb mRNA EXPRESSION}

Expression levels and basic statistical comparisons of $B d n f$ and Trkb transcripts are presented in Table 3 . In three of the four hippocampal sub-regions examined for Bdnf mRNA expression, Ex rats displayed significantly greater expression than Sed animals when controlling for Stress Treatment, as shown by Two-Way (Activity Status $\times$ Stress Treatment) ANOVAs. These included the CA3 region [main effect of Activity Status: $F_{(1,42)}=17.22$, $p=0.0002$ ] and the dorsal [Activity Status: $F_{(1,40)}=33.04, p<$ 0.0001 ] and ventral [Activity Status: $F_{(1,42)}=27.70, p<0.0001$ ] blades of the dentate gyrus. Relatively low levels of $B d n f$ mRNA were expressed in the CA1 region that did not differ reliably between the experimental groups. Although not statistically significant, a general pattern in hippocampal Bdnf mRNA expression emerged such that, in Sed rats, acute and repeated noise had a tendency to decrease expression relative to non-stressed controls, while Ex animals appeared to be buffered from this stress-induced reduction in hippocampal $B d n f$ transcription (see panels N-P of Figure 2). Figure 4 depicts $B d n f$ mRNA expression levels in the CA1 region, which serves to clearly illustrate this pattern of results. Expression of Bdnf mRNA was also examined in the PVN, in which a Two-Way ANOVA uncovered no reliable group differences. A significant main effect of Activity Status was revealed by Two-Way ANOVAs on Trkb mRNA expression in the CA1 $\left[F_{(1,42)}=8.63, p=0.0053\right]$ and CA3 $\left[F_{(1,42)}=5.37\right.$, $p=0.0254]$ hippocampal sub-regions, such that mRNA levels 


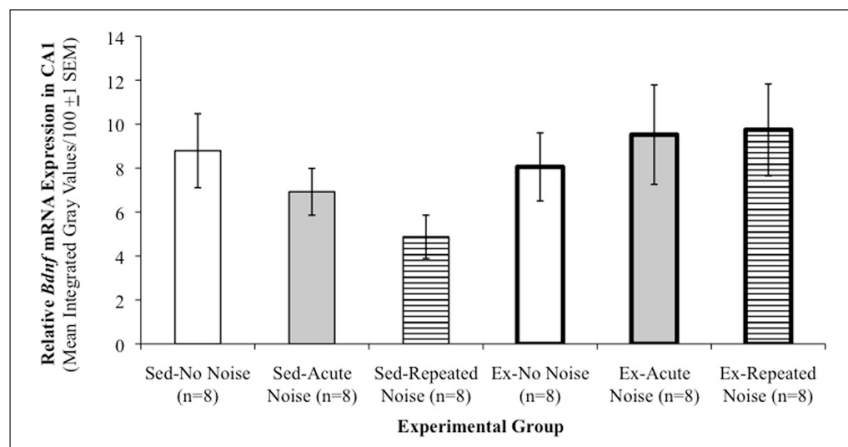

FIGURE 4 | Exercised rats appear less susceptible to stress-induced decreases in hippocampal Bdnf. Relative Bdnf mRNA expression levels in the CA1 sub-region of the hippocampus. Although group differences did not achieve statistical significance, a general pattern in Bdnf mRNA expression clearly emerged in this and the other three hippocampal sub-regions examined that is well-demonstrated by this particular figure, in that Ex rats did not appear to be susceptible to the same acute or repeated stress-induced decreases in hippocampal Bdnf mRNA expression that were exhibited in the Sed animals. Group means are mean integrated gray values/100 ( \pm 1 s.e.m.), presented as arbitrary units.

were significantly greater in Ex compared to Sed rats (Scheffé, $p$ 's $\leq$ 0.05). No reliable group differences in Trkb mRNA expression were observed in either the dorsal or ventral blades of the dentate gyrus.

\section{DISCUSSION}

The results of this study indicate that physical activity can significantly alter central nervous system expression patterns of several genes strongly associated with stress responsiveness. As summarized below, a number of studies have already identified various genes that are differentially regulated in the brains of physically active compared to sedentary rats under control (no stress) conditions. Importantly, some of this regulation can be further differentiated in exercised and sedentary brains in response to acute or repeated stress exposures. In view of our recent findings that prior physical activity enhances the rate of neuroendocrine and autonomic response habituation to repeated stress (Sasse et al., 2008; Nyhuis et al., 2010; Masini et al., 2011), we reasoned that these previously reported sites and molecular targets of regulation could also underlie this particular mode of stress adaptation. While the brains analyzed in the current study were obtained following measurements of HPA axis activation (Sasse et al., 2008), a nearly identical experimental protocol led to significantly facilitated habituation of heart rate and core body temperature responses in exercised rats (Masini et al., 2011). It is therefore highly likely that the central gene regulation observed in the current study could be associated with modulation of either or both the neuroendocrine and autonomic response adaptations observed in our prior studies.

\section{REGIONAL Fos mRNA INDUCTION AND HABITUATION}

As reported previously (Campeau et al., 1997, 2002; Campeau and Watson, 1997; Burow et al., 2005), acute loud noise exposure induced widespread Fos mRNA induction, but importantly, the amplitude of this expression did not differ between exercised and sedentary rats. This finding supports a number of prior studies reporting that acute HPA axis (Dishman et al., 1995, 1997, 1998; Fleshner, 2000; Fediuc et al., 2006; Sasse et al., 2008; Campeau et al., 2010; Nyhuis et al., 2010) and autonomic (Morimoto et al., 2000; Salam et al., 2009; Masini et al., 2011) responses to stress do not always differ between sedentary and more active animals. These indices of neuronal activation provide further evidence that general central responsiveness to acute stress can be preserved in exercising animals, which is important given the critical role of stress responses in adaptation and survival (Munck et al., 1984; Levine and Ursin, 1991; Chrousos and Gold, 1992; Akil and Morano, 1995). Notably, whereas our previous work demonstrated enhanced HPA axis (Sasse et al., 2008; Nyhuis et al., 2010) and autonomic (Masini et al., 2011) response habituation to repeated stress exposures in exercised animals, the quantified brain regions of Ex and Sed rats did not exhibit significant differences in Fos mRNA induction immediately following the final (11th) repeated noise exposure. This general result may reflect the fact that brains were collected at a point during repeated stress exposures at which the neuroendocrine and autonomic response differences between exercised and sedentary rats have mostly dissipated (Sasse et al., 2008; Nyhuis et al., 2010; Masini et al., 2011). Future studies should include earlier time-points during repeated stress exposures (3rd-8th exposures) when HPA axis and autonomic response differences are observed. In addition, although non-significant, an interesting pattern emerged in the brains of exercised animals, such that acute and especially repeated noise stress appeared to decrease Fos mRNA induction in prefrontal cortical regions relative to that of No Noise controls (see Table 1). Prior associations with motivated behaviors (Cardinal et al., 2002) and stress adaptation (Campeau et al., 2002; Weinberg et al., 2009) make these regions important targets for future studies of the impact of physical activity on stress adaptation.

\section{Crh AND Avp EXPRESSION IN THE PARAVENTRICULAR HYPOTHALAMIC NUCLEUS}

In the PVN, stress-induced release of CRH and AVP peptides are typically accompanied by increases in their gene transcription (Herman et al., 1992; Kovács and Sawchenko, 1996; Ma et al., 1997; Girotti et al., 2006) and subsequent elevations of steady state mRNA levels (Herman et al., 1992; Luo et al., 1994; Makino et al., 1995). It was therefore surprising to observe the lowest PVN-Crh mRNA levels in the Sed-Acute Noise group relative to that of the other Sed groups. However, PVN-Crh mRNA increases are typically observed 1-4 h after stress onset (Herman et al., 1992; Luo et al., 1994; Ma et al., 1997) and thus may have been missed given the shorter 30 min interval employed in the current study. This may also explain the lack of a Stress Treatment effect on the expression of $A v p$ mRNA in the PVN, as elevation in Avp transcription is further delayed compared to that of $\mathrm{Crh}$ (Herman et al., 1992; Kovács and Sawchenko, 1996; Ma et al., 1997). An alternative explanation might be provided by unusually elevated Crh mRNA expression levels in the Sed-No Noise rats. Importantly, the lack of differences in plasma corticosterone concentrations between exercised and sedentary rats under basal conditions, after acute stress exposure, and following 11 days of 
repeated stress exposures (Sasse et al., 2008; Nyhuis et al., 2010) suggests that observed differences in PVN-Crh mRNA exerted little influence on HPA axis tone or sensitivity. Repeated stress is also reported to elevate Crh mRNA expression in the PVN (Aguilera, 1994; Herman et al., 1995; Gómez et al., 1996), yet the comparatively milder repeated noise stress paradigm used here did not produce significant increases in PVN-Crh or Avp mRNA expression in sedentary or exercised rats. The similar expression levels of these principal hypothalamic regulators of stress responses between exercised and sedentary rats therefore argues against an important role for these hypophysiotropic signals in the differential rates of stress adaptation we have observed (Sasse et al., 2008; Nyhuis et al., 2010; Masini et al., 2011).

\section{EXTRA-HYPOTHALAMIC Crh REGULATION}

Crh mRNA expression was examined in three additional, extrahypothalamic regions, including the central amygdala and the dorsal and ventral BNST. Previous studies have demonstrated that both acute and repeated stress activate the CRH systems in these regions (Chappell et al., 1986; Merali et al., 1998; Makino et al., 1999; Figueiredo et al., 2003) and have established important roles for their recruitment in mediating the expression and integration of behavioral and autonomic components of the stress response (Fisher et al., 1982; Koob et al., 1993). Each of these three regions exhibited a similar and interesting pattern of Crh regulation, in which expression was generally decreased by repeated noise stress in sedentary rats but was relatively unaffected, if not increased (although non-significantly), in voluntarily exercising animals exposed to the same repeated stress paradigm. The relatively short, $30 \mathrm{~min}$ interval between stress onset and euthanasia may again account for the lack of clear acute stress effects in these regions when compared to prior studies (Chappell et al., 1986; Merali et al., 1998; Makino et al., 1999; Figueiredo et al., 2003). Based on the results obtained in the Sed groups, one might hypothesize that a decrease in extra-hypothalamic $\mathrm{CRH}$ contributes to response habituation to repeated stress exposures. If this were the case, an even greater reduction in extra-hypothalamic Crh transcript would be expected in the ExRepeated Noise group, since response habituation to repeated noise was enhanced in these animals relative to their sedentary counterparts (Sasse et al., 2008; Nyhuis et al., 2010; Masini et al., 2011), but this was not observed. Whether and how differential regulation of these extra-hypothalamic influences contributes to the different rates of response habituation exhibited by exercised and sedentary rats remains an open question.

\section{REGULATION OF Crh RECEPTORS}

Expression levels of Crhrl mRNA in the medial and basolateral amygdala were similar between Ex and Sed groups, and were relatively insensitive to the different Stress Treatment conditions of this experiment, which is consistent with previous observations (Van Pett et al., 2000). In the PVN, Crhrl mRNA is typically expressed at very low levels basally, although several groups have reported inducible expression of PVN-Crhrl following exposure to a variety of different stressors (Luo et al., 1994; Makino et al., 1995; Rivest et al., 1995; Imaki et al., 1996; Van Pett et al., 2000). The only reliable difference in Crhrl expression observed in this study was exhibited in the PVN specifically of Ex rats, with significantly greater expression in the Repeated Noise compared to the Acute Noise group (although neither group differed significantly from No Noise controls). While others have demonstrated Crhr1 mRNA induction in the PVN several hours following stressor onset (e.g., Van Pett et al., 2000), its expression was below the threshold of detection in the PVN of both Ex and Sed rats $30 \mathrm{~min}$ after acute noise onset. It thus remains possible that differential regulation of PVN-Crhrl might be revealed at later time-points following acute stress exposure.

Exploration of Crhr2 mRNA expression, which is regionally more limited than that of Crhr1 (Chalmers et al., 1995; Van Pett et al., 2000), did not reveal any differences in the lateral septum or medial amygdala. However, Crhr2 mRNA expression was significantly reduced in the ventromedial hypothalamic nucleus of exercised compared to sedentary groups. Since Crhr2 signaling in this region has previously been implicated in the regulation of food intake and energy balance (Steller, 1954; Spina et al., 1996), and significant alterations in these same measures are consistently reported in voluntarily exercising rats (Tokuyama et al., 1982; Rodnick et al., 1989; Afonso and Eikelboom, 2003), this finding may be important for future studies aimed at unraveling the complex metabolic adaptations associated with regular exercise.

\section{EFFECTS WITHIN THE BDNF-TRKB SIGNALING SYSTEM}

In three of the four hippocampal sub-regions in which $B d n f$ mRNA levels were assessed, expression was significantly greater in Ex compared to Sed rats. This finding is consistent with several other reports of increased hippocampal $B d n f$ expression in voluntarily exercising animals, both at the mRNA (Neeper et al., 1996; Oliff et al., 1998; Farmer et al., 2004; Gomez-Pinella et al., 2008; Nyhuis et al., 2010) and protein levels (Adlard and Cotman, 2004). Further, although stress has been demonstrated to reduce $B d n f$ expression in the hippocampus and PVN (Smith et al., 1995a,b; Nibuya et al., 1999; Adlard and Cotman, 2004), only non-significant reductions were observed here, particularly in the Sed-Repeated Noise rats. Importantly, the general trends we observed in the hippocampus were consistent with previously published results, in that voluntary exercise appeared to prevent the non-significant stress-induced decreases in hippocampal $B d n f$ mRNA expression observed in sedentary animals. Similarly, greater Trkb mRNA levels were expressed in the CA1 and CA3 pyramidal cell layers of Ex compared to Sed rats. Taken together, the exercise-induced increases in both ligand $(B d n f)$ and receptor $(T r k b)$ transcripts in the present study are suggestive of an enhanced capacity for expression of the neuroprotective and synapse-strengthening functions of this signaling system. However, the overall lack of significant stress or interaction effects implies that the observed differences in hippocampal $B d n f$ and Trkb mRNA expression are not likely to provide the key neural substrate(s) directly mediating differential stress response habituation in exercised and sedentary rats.

\section{CONCLUSIONS}

This study provided a starting point for the elucidation of neurochemical mechanisms potentially underlying exercise-induced 
facilitation of glucocorticoid and cardiovascular response habituation to repeated audiogenic stress exposures that were recently reported (Sasse et al., 2008; Nyhuis et al., 2010; Masini et al., 2011). The primary conclusion that can be drawn from these results is that the brains of sedentary and physically active animals respond in multiple different ways to acute and repeated stress exposures. It is likely that some of the central changes reported here mediate various exercise-induced physiological adaptations (i.e., metabolic regulation). Additional direct intervention studies will be required to determine whether or how these observed brain modifications contribute to the enhanced rate of stress response habituation observed in exercised animals. Because it is the situations involving prolonged or repeated stress that are most strongly associated with illness, the possibility that interventions as cost-effective as regular exercise could enhance the rate of adaptation of potentially deleterious physiological responses to such situations strongly indicates the need for further investigation.

\section{AUTHOR CONTRIBUTIONS}

Sarah K. Sasse performed the animal experiment with significant technical contributions from Tara J. Nyhuis, Cher V. Masini, Heidi E. W. Day and Serge Campeau. All in situ hybridization histochemistry was conducted by Sarah K. Sasse and Tara J. Nyhuis. Data analysis was performed by Sarah K. Sasse and interpreted by Sarah K. Sasse and Serge Campeau. Sarah K. Sasse and Serge Campeau wrote the manuscript.

\section{ACKNOWLEDGMENTS}

This study was supported by NINDS R03NS054358 (Serge Campeau).

\section{REFERENCES}

Adlard, P. A., and Cotman, C. W. (2004). Voluntary exercise protects against stressinduced decreases in brain derived neurotrophic factor protein expression. Neuroscience 124, 985-992. doi: 10.1016/j.neuroscience.2003.12.039

Afonso, V. M., and Eikelboom, R. (2003). Relationship between wheel running, feeding, drinking, and body weight in male rats. Physiol. Behav. 80, 19-26. doi: 10.1016/S0031-9384(03)00216-6

Aguilera, G. (1994). Regulation of pituitary ACTH secretion during chronic stress. Front. Neuroendocrinol. 15, 321-350. doi: 10.1006/frne.1994.1013

Akana, S. F., and Dallman, M. F. (1997). Chronic cold in adrenalectomized, corticosterone (B)-treated rats: facilitated corticotropin responses to acute restraint emerge as B increases. Endocrinology 138, 3249-3258. doi: 10.1210/en.138.8.3249

Akil, H., and Morano, M. I. (1995). "Stress," in Psychopharmacology: The Fourth Generation of Progress, eds F. Bloom and D. Kupfer (New York, NY: Raven Press, Ltd.), 773-785.

Antoni, F. A. (1993). Vasopressinergic control of pituitary adrenocorticotropin secretion comes of age. Front. Neuroendocrinol. 14, 76-122. doi: 10.1006/frne.1993.1004

Arborelius, L., Owens, M. J., Plotsky, P. M., and Nemeroff, C. B. (1999). The role of corticotropin-releasing factor in depression and anxiety disorders. J. Endocrinol. 160, 1-12. doi: 10.1677/joe.0.1600001

Armario, A., Castellanos, J. M., and Balasch, J. (1984). Adaptation of anterior pituitary hormones to chronic noise stress in male rats. Behav. Neural Biol. 41, 71-76. doi: 10.1016/S0163-1047(84)90745-3

Armario, A., Hidalgo, J., and Giralt, M. (1988). Evidence that the pituitaryadrenal axis does not cross-adapt to stressors: comparison to other physiological variables. Neuroendocrinology 47, 263-267. doi: 10.1159/000124921

Armario, A., Lopez-Calderón, A., Jolin, T., and Balasch, J. (1986). Response of anterior pituitary hormones to chronic stress. The specificity of adaptation. Neurosci. Biobehav. Rev. 10, 245-250. doi: 10.1016/0149-7634(86)90011-4
Bérard, A., Bravo, G., and Gauthier, P. (1997). Meta-analysis of the effectiveness of physical activity for the prevention of bone loss in postmenopausal women. Osteoporos. Int. 7, 331-337. doi: 10.1007/BF01623773

Brindley, D., and Rolland, Y. (1989). Possible connections between stress, diabetes, obesity, hypertension and altered lipoprotein metabolism that may result in atherosclerosis. Clin. Sci. (Lond.) 77, 453-461.

Brown, G. W., Bifulco, A., and Harris, T. O. (1987). Life events, vulnerability and onset of depression. Brit. J. Psychiat. 150, 30-42. doi: 10.1192/bjp.150.1.30

Brown, J. D., and Lawton, M. (1986). Stress and well-being in adolescence: the moderating role of physical role of physical exercise. J. Hum. Stress 12, 125-131.

Brown, J. D., and Siegel, J. M. (1988). Exercise as a buffer of life stress: a prospective study of adolescent health. Health Psychol. 7, 341-353. doi: 10.1037/02786133.7.4.341

Burow, A., Day, H. E., and Campeau, S. (2005). A detailed characterization of loud noise stress: Intensity analysis of hypothalamo-pituitary-adrenocortical axis and brain activation. Brain Res. 1062, 63-73. doi: 10.1016/j.brainres.2005.09.031

Campeau, S., Akil, H., and Watson, S. J. (1997). Lesions of the medial geniculate nuclei specifically block corticosterone release and induction of c-fos mRNA in the forebrain associated with audiogenic stress in rats. J. Neurosci. 17, 5979-5992.

Campeau, S., Dolan, D., Akil, H., and Watson, S. J. (2002). c-fos mRNA induction in acute and chronic audiogenic stress: possible role of the orbitofrontal cortex in habituation. Stress 5, 121-130. doi: 10.1080/10253890290027895

Campeau, S., Nyhuis, T. J., Sasse, S. K., Kryskow, E. M., Herlihy, L., Babb, J. A., et al. (2010). Hypothalamic pituitary adrenal axis responses to low-intensity stressors are reduced after voluntary wheel running in rats. J. Neuroendocrinol. 22, 872-888. doi: 10.1111/j.1365-2826.2010.02007.x

Campeau, S., and Watson, S. J. (1997). Neuroendocrine and behavioral responses and brain pattern of c-fos induction associated with audiogenic stress. J. Neuroendocrinol. 9, 577-588.

Campisi, J., and Fleshner, M. (2003). Role of extracellular HSP72 in acute stressinduced potentiation of innate immunity in active rats. J. Appl. Physiol. 94, 43-52. doi: 10.1152/japplphysiol.00681.2002

Cardinal, R. N., Parkinson, J. A., Hall, J., and Everitt, B. J. (2002). Emotion and motivation: the role of the amygdala, ventral striatum, and prefrontal cortex. Neurosci. Biobehav. Rev. 26, 321-352. doi: 10.1016/S0149-7634(02) 00007-6

Chalmers, D. T., Lovenberg, T. W., and De Souza, E. B. (1995). Localization of novel corticotropin-releasing factor receptor (CRF2) mRNA expression to specific subcortical nuclei in rat brain: comparison with CRF1 receptor mRNA expression. J. Neurosci. 15, 6340-6350.

Chappell, P. B., Smith, M. A., Kilts, C. D., Bissette, G., Ritchie, J., Anderson, C., et al. (1986). Alterations in corticotropin-releasing factor-like immunoreactivity in discrete brain regions after acute and chronic stress. J. Neurosci. 6, 2908-2914.

Charmandari, E., Tsigos, C., and Chrousos, G. P. (2005). Endocrinology of the stress response. Annu. Rev. Physiol. 67, 259-284. doi: 10.1146/annurev.physiol.67.040403.120816

Chodzko-Zajko, W. J., and Moore, K. A. (1994). Physical fitness and cognitive functioning in aging. Exerc. Sport Sci. Rev. 22, 195-220. doi: 10.1249/00003677199401000-00009

Chrousos, G. P., and Gold, P. W. (1992). The concepts of stress and stress system disorders. Overview of physical and behavioral homeostasis. J. Am. Med. Assoc. 267, 1244-1252. doi: 10.1001/jama.1992.03480090092034

Day, H. E., Nebel, S., Sasse, S., and Campeau, S. (2005). Inhibition of the central extended amygdala by loud noise and restraint stress. Eur. J. Neurosci. 21, 441-454. doi: 10.1111/j.1460-9568.2005.03865.x

Dishman, R. K., Bunnell, B. N., Youngstedt, S. D., Yoo, H. S., Mougey, E. H., and Meyerhoff, J. L. (1998). Activity wheel running blunts increased plasma adrenocorticotrophin (ACTH) after footshock and cage-switch stress. Physiol. Behav. 63, 911-917. doi: 10.1016/S0031-9384(98)00017-1

Dishman, R. K., Renner, K. J., Youngstedt, S. D., Reigle, T. G., Bunnell, B. N., Burke, K. A., et al. (1997). Activity wheel running reduces escape latency and alters brain monoamine levels after footshock. Brain Res. Bull. 42, 399-406. doi: 10.1016/S0361-9230(96)00329-2

Dishman, R. K., Warren, J. M., Youngstedt, S. D., Yoo, H., Bunnell, B. N., Mougey, E. H., et al. (1995). Activity-wheel running attenuates suppression of natural killer cell activity after footshock. J. Appl. Physiol. 78, 1547-1554.

Dong, H. W., and Swanson, L. W. (2006). Projections from bed nuclei of the stria terminalis, dorsomedial nucleus: implications for cerebral hemisphere 
integration of neuroendocrine, autonomic, and drinking responses. J. Comp. Neurol. 494, 75-107. doi: 10.1002/cne.20790

Droste, S. K., Chandramohan, Y., Hill, L. E., Linthorst, A. C., and Reul, J. M. (2007). Voluntary exercise impacts on the rat hypothalamic-pituitaryadrenocortical axis mainly at the adrenal level. Neuroendocrinology 86, 26-37. doi: $10.1159 / 000104770$

Droste, S. K., Gesing, A., Ulbricht, S., Müller, M. B., Linthorst, A. C., and Reul, J. M. (2003). Effects of long-term voluntary exercise on the mouse hypothalamic-pituitary-adrenocortical axis. Endocrinology 144, 3012-3023. doi: 10.1210/en.2003-0097

Droste, S. K., Schweizer, M. C., Ulbricht, S., and Reul, J. M. (2006). Longterm voluntary exercise and the mouse hypothalamic-pituitary-adrenocortical axis: impact of concurrent treatment with the antidepressant drug tianeptine. J. Neuroendocrinol. 18, 915-925. doi: 10.1111/j.1365-2826.2006.01489.x

Dunn, A. L., Trivedi, M. H., and O'Neal, H. A. (2001). Physical activity doseresponse effects on outcomes of depression and anxiety. Med. Sci. Sports Exerc. 33(6 Suppl.), S587-S597. doi: 10.1097/00005768-200106001-00027

Dunner, D., Patrick, V., and Fieve, R. R. (1979). Life events at the onset of bipolar affective illness. Am. J. Psychiat. 136, 508-511.

Esdin, J., Pearce, K., and Glanzman, D. L. (2010). Long-term habituation of the gill-withdrawal reflex in aplysia requires gene transcription, calcineurin and L-type voltage-gated calcium channels. Front. Behav. Neurosci. 4:181. doi: 10.3389/fnbeh.2010.00181

Ezzeddine, Y., and Glanzman, D. L. (2003). Prolonged habituation of the gillwithdrawal reflex in Aplysia depends on protein synthesis, protein phosphatase activity, and postsynaptic glutamate receptors. J Neurosci. 23, 9585-9594.

Farmer, J., Zhao, X., van Praag, H., Wodtke, K., Gage, F. H., and Christie, B. R. (2004). Effects of voluntary exercise on synaptic plasticity and gene expression in the dentate gyrus of adult male sprague-dawley rats in vivo. Neuroscience 124, 71-79. doi: 10.1016/j.neuroscience.2003.09.029

Fediuc, S., Campbell, J. E., and Riddell, M. C. (2006). Effect of voluntary wheel running on circadian corticosterone release and on HPA axis responsiveness to restraint stress in Sprague-Dawley rats. J. Appl. Physiol. 100, 1867-1875. doi: 10.1152/japplphysiol.01416.2005

Figueiredo, H. F., Bodie, B. L., Tauchi, M., Dolgas, C. M., and Herman, J. P. (2003), Stress integration after acute and chronic predator stress: differential activation of central stress circuitry and sensitization of the hypothalamo-pituitaryadrenocortical axis. Endocrinology 144, 5249-5258. doi: 10.1210/en.2003-0713

Fisher, L. A., Rivier, J., Rivier, C., Spiess, J., Vale, W., and Brown, M. R. (1982). Corticotropin-releasing factor (CRF): central effects on mean arterial pressure and heart rate in rats. Encocrinology 110, 2222-2224. doi: 10.1210/endo$110-6-2222$

Fleshner, M. (2000). Exercise and neuroendocrine regulation of antibody production: protective effect of physical activity on stress-induced suppression of the specific antibody response. Int. J. Sports Med. 21(Suppl. 1), S14-S19. doi: 10.1055/s-2000-1454

Fleshner, M. (2005). Physical activity and stress resistance: sympathetic nervous system adaptations prevent stress-induced immunosuppression. Exerc. Sport. Sci. Rev. 33, 120-126. doi: 10.1097/00003677-200507000-00004

Forsen, A. (1991). Psychosocial stress as a risk for breast cancer. Psychother. Psychosom. 55, 176-185. doi: 10.1159/000288427

Girotti, M., Pace, T. W., Gaylord, R. I., Rubin, B. A., Herman, J. P., and Spencer, R. L. (2006). Habituation to repeated restraint stress is associated with lack of stress-induced c-fos expression in primary sensory processing areas of the rat brain. Neuroscience 138, 1067-1081. doi: 10.1016/j.neuroscience.2005.12.002

Gómez, F., Lahmame, A., de Kloet, E. R., and Armario, A. (1996). Hypothalamicpituitary-adrenal response to chronic stress in five inbred rat strains: differential responses are mainly located at the adrenocortical level. Neuroendocrinology 63 , 327-337. doi: 10.1159/000126973

Gomez-Pinella, F., Vaynman, S., and Ying, Z. (2008). Brain-derived neurotrophic factor functions as a metabotrophin to mediate the effects of exercise on cognition. Eur. J. Neurosci. 28, 2278-2287. doi: 10.1111/j.1460-9568.2008. 06524.x

Goodwin, R. D. (2003). Association between physical activity and mental disorders among adults in the United States. Prev. Med. 36, 698-703. doi: 10.1016/S0091$7435(03) 00042-2$

Greenwood, B. N., Foley, T. E., Day, H. E. W., Campisi, J., Hammack, S. H., Campeau, S., et al. (2003a). Freewheel running prevents learned helplessness/behavioral depression: role of dorsal raphe serotonergic neurons. J. Neurosci. 23, 2889-2898.

Greenwood, B. N., Kennedy, S., Smith, T. P., Campeau, S., Day, H. E. W., and Fleshner, M. (2003b). Voluntary freewheel running selectively modulates catecholamine content in peripheral tissue and c-fos expression in the central sympathetic circuit following exposure to uncontrollable stress in rats. Neuroscience 120, 269-281. doi: 10.1016/S0306-4522(03)00047-2

Greenwood, B. N., Strong, P. V., Dorey, A. A., and Fleshner, M. (2007a). Therapeutic effects of exercise: wheel running reverses stress-induced interference with shuttle box escape. Behav. Neurosci. 121, 992-1000. doi: 10.1037/0735-7044.121.5.992

Greenwood, B. N., Strong, P. V., Foley, T. E., Thompson, R. S., and Fleshner, M. (2007b). Learned helplessness is independent of levels of brain-derived neurotrophic factor in the hippocampus. Neuroscience 144, 1193-1208. doi: 10.1016/j.neuroscience.2006.11.007

Gu, G., Cornea, A., and Simerly, R. B. (2003). Sexual differentiation of projections from the principal nucleus of the bed nuclei of the stria terminalis. J. Comp. Neurol. 460, 542-562. doi: 10.1002/cne.10677

Hammen, C., Davila, J., Brown, G., Ellicott, A., and Gitlin, M. (1992). Psychiatric history and stress: predictors of severity of unipolar depression. J. Abnorm. Psychol. 101, 45-52. doi: 10.1037/0021-843X.101.1.45

Hauger, R. L., Risbrough, V., Brauns, O., and Dautzenberg, F. M. (2006). Corticotropin releasing factor (CRF) receptor signaling in the central nervous system: new molecular targets. CNS Neurol. Disord. Drug Targets 5, 453-479. doi: $10.2174 / 187152706777950684$

Herman, J. P., Adams, D., and Prewitt, C. (1995). Regulatory changes in neuroendocrine stress-integrative circuitry produced by a variable stress paradigm. Neuroendocrinology 61, 180-190. doi: 10.1159/000126839

Herman, J. P., Schafer, M. K., Thompson, R. C., and Watson, S. J. (1992). Rapid regulation of corticotropin-releasing hormone gene transcription in vivo. Mol. Endocrinol. 6, 1061-1069. doi: 10.1210/me.6.7.1061

Imaki, T., Naruse, M., Harada, S., Chikada, N., Imaki, J., Onodera, H., et al. (1996). Corticotropin-releasing factor up-regulates its own receptor mRNA in the paraventricular nucleus of the hypothalamus. Brain Res. Mol. Brain Res. 38, 166-170. doi: 10.1016/0169-328X(96)00011-3

Kalantaridou, S. N., Makrigiannakis, A., Zoumakis, E., and Chrousos, G. P. (2004). Stress and the female reproductive system. J. Reprod. Immunol. 62, 61-68. doi: 10.1016/j.jri.2003.09.004

Kant, G. J., Eggleston, T., Landman-Roberts, L., Kenion, C. C., Driver, G. C., and Meyerhoff, J. L. (1985). Habituation to repeated stress is stressor specific. Pharmacol. Biochem. Behav. 22, 631-634. doi: 10.1016/0091-3057(85)90286-2

Kawashima, H., Saito, T., Yoshizato, H., Fujikawa, T., Sato, Y., McEwen, B. S., et al. (2004). Endurance treadmill training in rats alters CRH activity in the hypothalamic paraventricular nucleus at rest and during acute running according to its period. Life Sci. 76, 763-774. doi: 10.1016/j.lfs.2004.09.014

Khansari, D. N., Murgo, A. J., and Faith, R. E. (1990). Effects of stress on the immune system. Immunol. Today 11, 170-175. doi: 10.1016/01675699(90)90069-L

Koob, G. F., Heinrichs, S. C., Pich, E. M., Menzaghi, F., Baldwin, H., Miczek, K., et al. (1993). The role of corticotropin-releasing factor in behavioural responses to stress. Ciba Foun. Symp. 172, 277-295.

Kovács, K. J., and Sawchenko, P. E. (1996). Regulation of stress-induced transcriptional changes in the hypothalamic neurosecretory neurons. J. Mol. Neurosci. 7, 125-133. doi: 10.1007/BF02736792

Levine, S., and Ursin, H. (1991). "What is stress?", in Stress: Neurobiology and Neuroendocrinology, eds M. R. Brown, G. F. Koob, and C. Rivier (New York, NY: Marcel Dekker, Inc.), 3-21.

Luo, X., Kiss, A., Makara, G., Lolait, S. J., and Aguilera, G. (1994). Stressspecific regulation of corticotropin releasing hormone receptor expression in the paraventricular and supraoptic nuclei of the hypothalamus in the rat. J. Neuroendocrinol. 6, 689-696. doi: 10.1111/j.1365-2826.1994.tb00636.x

Makino, S., Schulkin, J., Smith, M. A., Pacák, K., Palkovits, M., and Gold, P. W. (1995). Regulation of corticotropin-releasing hormone receptor messenger ribonucleic acid in the rat brain and pituitary by glucocorticoids and stress. Endocrinology 136, 4517-4525. doi: 10.1210/en.136.10.4517

Makino, S., Shibasaki, T., Yamauchi, N., Nishioka, T., Mimoto, T., Wakabayashi, I., et al. (1999). Psychological stress increased corticotropin-releasing hormone mRNA and content in the central nucleus of the amygdala but not in the 
hypothalamic paraventricular nucleus in the rat. Brain Res. 850, 136-143. doi: 10.1016/S0006-8993(99)02114-9

Manson, J. E., Nathan, D. M., Krolewski, A. S., Stampfer, M. J., Willett, W. C., and Hennekens, C. H. (1992). A prospective study of exercise and incidence of diabetes among US male physicians. J. Am. Med. Assoc. 268, 63-67. doi: 10.1001/jama.1992.03490010065031

Masini, C. V., Nyhuis, T. J., Sasse, S. K., Day, H. E., and Campeau, S. (2011). Effects of voluntary wheel running on heart rate, body temperature, and locomotor activity in response to acute and repeated stressor exposures in rats. Stress 14 , 324-334. doi: 10.3109/10253890.2010.548013

Ma, X. M., Levy, A., and Lightman, S. L. (1997). Rapid changes in heteronuclear RNA for corticotrophin-releasing hormone and arginine vasopressin in response to acute stress. J. Endocrinol. 152, 81-89. doi: 10.1677/joe.0. 1520081

Melia, K. R., Ryabinin, A. E., Schroeder, R., Bloom, F. E., and Wilson, M. C. (1994). Induction and habituation of immediate early gene expression in rat brain by acute and repeated restraint stress. J. Neurosci. 14, 5929-5938.

Merali, Z., McIntosh, J., Kent, P., Michaud, D., and Anisman, H. (1998). Aversive and appetitive events evoke the release of corticotropin-releasing hormone and bombesin-like peptides at the central nucleus of the amygdala. J. Neurosci. 18, 4758-4766.

Moraska, A., and Fleshner, M. (2001). Voluntary physical activity prevents stressinduced behavioral depression and anti-KLH antibody suppression. Am. J. Physiol. Regul. Integr. Comp. Physiol. 281, R484-R489.

Morimoto, K., Tan, N., Nishiyasu, T., Sone, R., and Murakami, N. (2000). Spontaneous wheel running attenuates cardiovascular responses to stress in rats. Pflugers Arch. 440, 216-222.

Munck, A., Guyre, P. M., and Holbrook, N. J. (1984). Physiological functions of glucocorticoids and their relation to pharmacological actions. Endocr. Rev. 5, 25-44. doi: 10.1210/edrv-5-1-25

National Research Council. (2011). Guide for the Care and Use of Laboratory Animals 8th, Edn, Washington, DC: National Academies Press.

Neeper, S. A., Gómez-Pinella, F., Choi, J., and Cotman, C. W. (1996). Physical activity increases mRNA for brain-derived neurotrophic factor and nerve growth factor in rat brain. Brain Res. 726, 49-56. doi: 10.1016/0006-8993(96)00273-9

Nibuya, M., Takahashi, M., Russell, D. S., and Duman, R. S. (1999). Repeated stress increases catalytic TrkB mRNA in rat hippocampus. Neurosci. Lett. 267, 81-84. doi: 10.1016/S0304-3940(99)00335-3

Nyhuis, T. J., Masini, C. V., Sasse, S. K., Day, H. E., and Campeau, S. (2010). Physical activity, but not environmental complexity, facilitates HPA axis response habituation to repeated audiogenic stress despite neurotrophin mRNA regulation in both conditions. Brain Res. 1362, 68-77. doi: 10.1016/j.brainres.2010.09.038

Oliff, H. S., Berchtold, N. C., Isackson, P., and Cotman, C. W. (1998). Exerciseinduced regulation of brain-derived neurotrophic factor (BDNF) transcripts in the rat hippocampus. Brain Res. Mol. Brain Res. 61, 147-153. doi: 10.1016/S0169-328X(98)00222-8

Paffenbarger, R. S. Jr., Lee, I. M., and Wing, A. L. (1992). The influence of physical activity on the incidence of site-specific cancers in college alumni. Adv. Exp. Med. Biol. 322, 7-15. doi: 10.1007/978-1-4684-7953-9 2 2

Park, E., Chan, O., Li, Q., Kiraly, M., Matthews, S. G., Vranic, M., et al. (2005). Changes in basal hypothalamo-pituitary-adrenal activity during exercise training are centrally mediated. Am. J. Physiol. Regul. Integr. Comp. Physiol. 289, R1360-R1371. doi: 10.1152/ajpregu.00103.2005

Pasternac, A., and Talajic, M. (1991). The effects of stress, emotion, and behavior on the heart. Methods Achiev. Exp. Pathol. 15, 47-57.

Paxinos, G., and Watson, C. (2005). The Rat Brain in Stereotaxic Coordinates, CDROM. San Diego, CA: Academic Press.

Radley, J. J., Gosselink, K. L., and Sawchenko, P. E. (2009). A discrete GABAergic relay mediates medial prefrontal cortical inhibition of the neuroendocrine stres response. J. Neurosci. 29, 7330-7340. doi: 10.1523/JNEUROSCI.5924-08.2009

Rivest, S., Laflamme, N., and Nappi, R. E. (1995). Immune challenge and immobilization stress induce transcription of the gene encoding the CRF receptor in selective nuclei of the rat hypothalamus. J. Neurosci. 15, 2680-2695.

Rodnick, K. J., Reaven, G. M., Haskell, W. L., Sims, C. R., and Mondon, C. E. (1989). Variations in running activity and enzymatic adaptations in voluntary running rats. J. Appl. Physiol. 66, 1250-1257.

Roth, D. L., and Holmes, D. S. (1985). Influence of physical fitness in determining the impact of stressful life events and physical and psychological health. Psychosom. Med. 47, 164-173.
Salam, J. N., Fox, J. H., Detroy, E. M., Guignon, M. H., Wohl, D. F., and Falls, W. A. (2009). Voluntary exercise in C57 mice is anxiolytic across several measures of anxiety. Behav. Brain Res. 197, 31-40. doi: 10.1016/j.bbr.2008.07.036

Sasse, S. K., Greenwood, B. N., Masini, C. V., Nyhuis, T. N., Fleshner, M., Day, H. E. W., et al. (2008). Chronic voluntary wheel running facilitates corticosterone response habituation to repeated audiogenic stress exposure in male rats. Stress 11, 425-437. doi: 10.1080/10253890801887453

Smith, M. A., Makino, S., Kim, S. Y., and Kvetnansky, R. (1995a). Stress increases brain-derived neurotrophic factor messenger ribonucleic acid in the hypothalamus and pituitary. Endocrinology 136, 3743-3750. doi: 10.1210/en.136.9.3743

Smith, M. A., Makino, S., Kvetnansky, R., and Post, R. M. (1995b). Stress and glucocorticoids affect the expression of brain-derived neurotrophic factor and neurotrophin-3 mRNAs in the hippocampus. J. Neurosci. 15(3 Pt 1), 1768-1777.

Spina, M., Merlo-Pich, E., Chan, R. K. W., Basso, A. M., Rivier, J., Vale, W., et al. (1996). Appetite-suppressing effects of urocortin, a CRF-related neuropeptide. Science 273, 1561-1564 doi: 10.1126/science. 273.5281.1561

Steller, E. (1954). The physiology of motivation. Physiol. Rev. 61, 5-22.

Swaab, D. F., Bao, A. M., and Lucassen, P. J. (2005). The stress system and the human brain in depression and neurodegeneration. Ageing Res. Rev. 4, 141-194. doi: 10.1016/j.arr.2005.03.003

Timofeeva, E., Huang, Q., and Richard, D. (2003). Effects of treadmill running on brain activation and the corticotropin-releasing hormone system. Neuroendocrinology 77, 388-405. doi: 10.1159/000071311

Tokuyama, K., Saito, M., and Okuda, H. (1982). Effects of wheel running on food intake and weight gain of male and female rats. Physiol. Behav. 28, 899-903. doi: 10.1016/0031-9384(82)90211-6

Tsigos, C., and Chrousos, G. P. (1994). Physiology of the hypothalamic-pituitaryadrenal axis in health and dysregulation in psychiatric and autoimmune disorders. Endocrinol. Metab. Clin. North Am. 23, 451-466.

Ulrich-Lai, Y. M., and Herman, J. P. (2009). Neural regulation of endocrine and autonomic stress responses. Nat. Rev. Neurosci. 10, 397-409. doi: $10.1038 / \mathrm{nrn} 2647$

Vanitallie, T. B. (2002). Stress: a risk factor for serious illness. Metabolis. 51, 40-45 doi: 10.1053/meta.2002.33191

Van Pett, K., Viau, V., Bittencourt, J. C., Chan, R. K., Li, H. Y., Arias, C., et al. (2000). Distribution of mRNAs encoding CRF receptors in brain and pituitary of rat and mouse. J. Comp. Neurol. 428, 191-212. doi: 10.1002/10969861(20001211)428:2<191::AID-CNE1>3.0.CO;2-U

Wannamethee, S. G., Shaper, A. G., and Walker, M. (1998). Changes in physical activity, mortality, and incidence of coronary heart disease in older men. Lancet 351, 1603-1608. doi: 10.1016/S0140-6736(97)12355-8

Weinberg, M. S., Bhatt, A. P., Girotti, M., Masini, C. V., Day, H. E., Campeau, S., et al. (2009). Repeated ferret odor exposure induces different temporal patterns of same-stressor habituation and novel-stressor sensitization in both hypothalamic-pituitary-adrenal axis activity and forebrain c-fos expression in the rat. Endocrinology 150, 749-761. doi: 10.1210/en.2008-0958

Conflict of Interest Statement: The authors declare that the research was conducted in the absence of any commercial or financial relationships that could be construed as a potential conflict of interest.

Received: 10 September 2013; accepted: 05 November 2013; published online: 25 November 2013.

Citation: Sasse SK, Nyhuis TJ, Masini CV, Day HEW and Campeau S (2013) Central gene expression changes associated with enhanced neuroendocrine and autonomic response habituation to repeated noise stress after voluntary wheel running in rats. Front. Physiol. 4:341. doi: 10.3389/fphys.2013.00341

This article was submitted to Clinical and Translational Physiology, a section of the journal Frontiers in Physiology.

Copyright (c) 2013 Sasse, Nyhuis, Masini, Day and Campeau. This is an openaccess article distributed under the terms of the Creative Commons Attribution License (CC BY). The use, distribution or reproduction in other forums is permitted, provided the original author(s) or licensor are credited and that the original publication in this journal is cited, in accordance with accepted academic practice. No use, distribution or reproduction is permitted which does not comply with these terms. 